Screening Program Reduced Melanoma Mortality at the Lawrence Livermore National Laboratory, 1984-1996

J. S. Schneider, MD, D. H. Moore II, PhD, M. L. Mendelsohn, MD, PhD

March 26, 2007

Journal of the American Academy of Dermatology 
This document was prepared as an account of work sponsored by an agency of the United States Government. Neither the United States Government nor the University of California nor any of their employees, makes any warranty, express or implied, or assumes any legal liability or responsibility for the accuracy, completeness, or usefulness of any information, apparatus, product, or process disclosed, or represents that its use would not infringe privately owned rights. Reference herein to any specific commercial product, process, or service by trade name, trademark, manufacturer, or otherwise, does not necessarily constitute or imply its endorsement, recommendation, or favoring by the United States Government or the University of California. The views and opinions of authors expressed herein do not necessarily state or reflect those of the United States Government or the University of California, and shall not be used for advertising or product endorsement purposes. 
Screening program reduced melanoma mortality at the Lawrence Livermore National

Formatted

\section{Laboratory, 1984-1996}

$\underline{\text { Running title: Melanoma screening program }}$

Jeffrey S. Schneider, MD ${ }^{1}$, Dan H. Moore II, $\mathrm{PhD}{ }^{2}$

Mortimer L. Mendelsohn, $\mathrm{MD}, \mathrm{PhD}^{3}$

From the ${ }^{1}$ Department of Dermatology, Kaiser Permanente Medical Center, San Rafael,

California; the ${ }^{1-3}$ Biomedical Sciences Division, Lawrence Livermore National Laboratory, Livermore, California; and the ${ }^{2}$ Research Institute, California Pacific Medical Center, San Francisco, California.

Presented as a Poster at the 62nd annual meeting of the American Academy of Dermatology, Washington, DC, February 6-11, 2004., and published in abstract form in J Am Acad Dermatol 2004 Mar;50 (3 Suppl).:P6.

Reprint requests: Jeffrey Schneider, MD, Department of Dermatology, Kaiser Permanente Medical Center, 99 Montecillo Road, San Rafael, CA 94903.

Phone: 415-444-2117; FAX: 415-444-2076; e-mail: Jeffrey.schneider@kp.org

Melanoma_Mort_jeff16Jun06 


\section{Abstract}

\section{Background}

Worldwide incidence of cutaneous malignant melanoma has increased substantially, and no screening program has yet demonstrated reduction in mortality. We evaluated the education, self examination and targeted screening campaign at the Lawrence Livermore National Laboratory (LLNL) from its beginning in July 1984 through 1996.

\section{$\underline{\text { Methods }}$}

The thickness and crude incidence of melanoma from the years before the campaign were compared to those obtained during the 13 years of screening. Melanoma mortality during the $13-$ year period was based on a National Death Index search. Expected yearly deaths from melanoma among LLNL employees were calculated by using California mortality data matched by age, sex, and race/ethnicity and adjusted to exclude deaths from melanoma diagnosed before the program began or before employment at LLNL.

$\underline{\text { Findings }}$

After the program began, crude incidence of melanoma thicker than $0.75 \mathrm{~mm}$ decreased from 18 to 4 cases per 100,000 person-years $(p=0.02)$, while melanoma less than $0.75 \mathrm{~mm}$ remained stable and in situ melanoma increased substantially. No eligible melanoma deaths occurred among LLNL employees during the screening period compared with a calculated 3.39 expected deaths $(\mathrm{p}=0.034)$.

$\underline{\text { Interpretation }}$

Education, self examination and selective screening for melanoma at LLNL significantly decreased incidence of melanoma thicker than $0.75 \mathrm{~mm}$ and reduced the melanoma-related mortality rate to zero. This significant decrease in mortality rate persisted for at least $3 \mathrm{yr}$ after employees retired or otherwise left the laboratory. 
Key words:

incidence

melanoma

occupational diseases

skin neoplasms 


\section{Introduction}

In the United States from 1975 to 2001, melanoma incidence increased 137\%, and mortality increased $29 \%{ }^{1}$. Many early detection campaigns were undertaken to reduce melanoma mortality. Most consisted of brief, no-charge skin screenings or publicity campaigns; these efforts showed increased numbers of thin tumors but did not evaluate mortality ${ }^{2}$. Population-based time series in England ${ }^{3}$,Scotland ${ }^{4}$ and Trentino, Italy ${ }^{6,7}$ involved education campaigns to teach identification of suspicious lesions to the local populations and medical community, encouraging people to be examined by medical personnel and helping to expedite referral and diagnosis. The English study showed an increase in thin tumors and no effect on mortality. The Italian program showed an increase in the proportion of thin tumors ${ }^{5}$ and suggested a possible reduction in mortality ${ }^{6}$. The Scottish study showed a temporary reduction in thick tumors and a stabilization of mortality rates among women and $\mathrm{men}^{4}{ }^{5}$. A large, randomized, controlled trial of melanoma screening in Australia is in its preliminary stage ${ }^{8}$.

In 1981, a three to fourfold excess incidence of melanoma during the period 1972-1977 was reported among the approximately 5100 persons then employed at the Lawrence Livermore National Laboratory (LLNL) in Northern California ${ }^{9}$. In response, a secondary melanoma prevention campaign began in 1984 and is ongoing. This campaign consists of employee education, self-examination, and targeted onsite screening conducted by a dermatologist.

We evaluated the LLNL melanoma screening and education program by comparing two endpoints: (1) thickness of diagnosed melanoma and (2) deaths from melanoma-beginning July 1984 through 1996 among LLNL employees and former employees.

\section{Methods}

Melanoma Education and Screening Program 
The LLNL education program began in July 1984 with instructions to employees about sun protection, signs of melanoma, and melanoma risk factors. This information was disseminated by direct mailings, worksite news articles, meetings and lectures to employees and local physicians.. The local news media responded with articles about the program. Employees were encouraged to examine themselves for suspicious lesions; if self-examination showed a suspicious lesion, a visit was arranged to the onsite screening facility for full-body examination, dermoscopy, and biopsy if indicated. Alternatively, personnel could be examined by their personal physicians, in which case the employees were encouraged to report results to the LLNL medical staff. All employees were also sent a form to report their mole counts at the outset of the program, and new employees received this form as part of their new-employee orientation at LLNL. Program participants who counted 5 or more moles $\geq 5 \mathrm{~mm}$ in diameter or a single mole $\geq 18 \mathrm{~mm}$ in diameter were offered a screening examination $^{10}$. Following the recommendations of the NIH Consensus Conference October 1983 Precursors to Malignant Melanoma, ${ }^{11}$ the two most atypical dysplastic nevi were considered for pathologic confirmation even if melanoma was not suspected. After the NIH Consensus Conference January $1992^{12}$, biopsies were only performed on atypical lesions to evaluate for melanoma. All examinations were performed by one of the authors (JSS) or by Fellows from the University of California, San Francisco Melanoma Clinic. After dermatologic evaluation, employees with melanoma (invasive or preinvasive), dysplastic nevi, 50 or more moles, or family history of melanoma were offered full-body periodic examination, every 3-24 months, often with full-body photography and dermoscopy, according to level of melanoma risk ${ }^{13}$. Melanoma thickness and crude incidence data

Institutional Review Board approval was obtained for all aspects of the study. Biopsy specimens obtained by the screening program at LLNL were evaluated at the UCSF Melanoma Center, and the thickness of each diagnosed melanoma was recorded. Any employees who reported 
an outside diagnosis of melanoma had their slides reviewed at UCSF. Crude incidence of melanoma was calculated for the pre-screening and screening periods stratified into 4 thickness categories: in situ, $\leq 0.75 \mathrm{~mm}, 0.75-1.50 \mathrm{~mm}$, and $>1.50 \mathrm{~mm}$. The pre-screening period was January 1969 through June 1984 and the screening period was July 1984 through December 1996. The denominator was the number of LLNL employees during the respective time periods.

\section{$\underline{\text { Mortality data models }}$}

A roster was compiled listing all LLNL employees with at least 6 months tenure from July 1984 through 1996. Roster information about employees and former employees-full name, date of birth, sex, and United States (US) social security number- was sent to the National Center for Health Statistics for matching with records in the National Death Index (NDI), a computerized database of records from the vital statistics offices of all US states and territories. Matches were confirmed independently using LLNL records. The NDI provided the coded cause of death for each probable match.

Annual California melanoma mortality rates for 1989 through 1996 were obtained online from Expert Health Data Programming, Inc ${ }^{14}$. Because the number of deaths in each subcategory was small, annual melanoma-related mortality rates were highly variable when subcategorized by sex, race, and 5-yr age subgroups. The rates were smoothed, using a Poisson regression model, before being applied to population at-risk data. Rates were extrapolated back from 1989 through 1984 using the same model.

Total number of melanoma deaths expected for the LLNL population was obtained by summing the products of calendar year/sex/race/age group smoothed rates and multiplying this product by the LLNL employee population. This calculation is shown mathematically by the equation

LLNL melanoma deaths $=\sum_{\mathrm{x}} \mathrm{R}_{\mathrm{x}} \mathrm{P}_{\mathrm{x}}$ 
where $R_{x}$ represents the calendar year/sex/race/age group smoothed rates and $P_{x}$ represents the corresponding calendar year/sex/race/age group-specific employee populations at LLNL. The summation includes all calendar year/sex/race/age groups.

We calculated cumulative mortality ${ }^{3}$ which excluded deaths among cases diagnosed prior to July 1984 or new hires who developed melanoma before employment at LLNL because they could not have benefited from the screening program. To account for this exclusion of pre-1984 case deaths in the study group, we adjusted the expected number of deaths by subtracting those likely to occur among cases diagnosed prior to 1984. This adjustment was based on observed melanoma mortality for the 5 San Francisco-Oakland Bay Area counties as reported to the Surveillance, Epidemiology and End Results (SEER) program. Table 1 shows the adjustment percentages for each year of the study.

We computed a second number of expected deaths on the basis of extending the number of person-years for LLNL employees 3 years beyond these employees' periods of LLNL employment or until 1996. In this computation, a number of years of "risk" beyond termination of LLNL employment was added for each employee. Employees and former employees who died from any cause were not included in the at-risk population beyond the year of the death.

\section{$\underline{\text { Statistical analysis of mortality data }}$}

Since the observed numbers of melanoma-related deaths can be considered rare events, they can be expected to follow a Poisson distribution when compared with the adjusted expected number of melanoma-related deaths. The probability that 0 events are observed is equal to $\mathrm{e}^{-\lambda}$ when $\lambda$ events are expected. This probability is approximately 0.05 when $\lambda=3$. 


\section{Results}

\section{Decreased incidence of high-risk melanoma}

From January 1969 through June 1984, 48 melanoma were diagnosed and 18 (38\%) of these measured $>0.75 \mathrm{~mm}$ thick. From these results, we calculated the crude incidence of these high-risk lesions to be 17.96 lesions per 100,000 person-years. From July 1984 through December 1996, 54 melanomas were diagnosed, and $5(9 \%)$ measured $>0.75 \mathrm{~mm}$ thick; these results yielded a crude incidence of 4.62 lesions per 100,000 person-years (Table 2). This series showed that the number of higher-risk melanoma lesions decreased markedly after screening began $(\mathrm{p}=0.02$ by Miettinen's exact test for the difference in crude rate with thickness $>0.75 \mathrm{~mm}$ ). We noted with particular interest that 3 of the 5 lesions thicker than $0.75 \mathrm{~mm}$ were diagnosed during the first year and that the other 2 lesions were diagnosed by the sixth year of the 12-year screening campaign (Table 2). The combined crude rate of invasive and in situ lesions remained stable over the 2 periods (46.91 vs 49.85 lesions per 100,000 person-years), but we observed a threefold increase in number of in situ melanomas and a stabilization of invasive melanomas $\leq 0.75 \mathrm{~mm}$.

\section{$\underline{\text { Decreased mortality from melanoma }}$}

A search of the NDI showed 3 melanoma-related deaths, all in people known to have the disease before either July 1984 or their date of being hired at LLNL. Therefore, the eligible mortality was zero with an upper $95 \%$ limit of 2.6 deaths.

Tables 3 and 4 show employee population by year and expected numbers of melanoma deaths among LLNL employees by sex, race, and year. During this period, no melanoma-related deaths were observed among LLNL employees who were not already diagnosed with melanoma 
before July 1984; and the probability of observing zero deaths is $p=0.034$ when 3.39 deaths are expected .

\section{Long-term effect of screening campaign}

The original study plan was to extend the analysis year-by-year beyond termination of LLNL employment. This was to account for possible melanoma deaths among LLNL employees who terminated their employment because of illness from melanoma. Secondarily this allowed for the analysis of possible decay of the education effect as terminees escaped LLNL melanomaprevention methods. This employee awareness might not diminish among terminees who retired with benefits from LLNL and continued to receive LLNL publications. However, no such melanoma deaths were observed, and terminees survived remarkably well from all causes during the study period. We therefore calculated the effect on $p$ value of three additional years of survival into retirement or until 1996. This calculation method increased the number of person-years under study from 113,715 to 149,474 . Because no melanoma deaths were observed and the expected number of melanoma deaths was 5.26, the probability of chance being an explanation was reduced to $\mathrm{p}=0.005$.

\section{Discussion}

The study confirmed a reduction in melanoma mortality in the LLNL workforce from July 1984 through December 1996 with 3.39 deaths expected from the California mortality data and no eligible cases observed. This result was markedly different from the high-but-not-significant increase in deaths noted in a previous national death certificate search at LLNL from 1964 through 1979, when 6 deaths were observed and 4 deaths were expected ${ }^{15}$.

Several potential limitations of this study were associated with its design and with the relatively small occupational setting. Ideally intervention would have been evaluated by a 
randomized controlled study. Individual randomization within LLNL was impossible given the goals of the program; and although comparison to outside sites was considered, no satisfactory comparable site was found. Therefore, the State of California whose very large population base can provide stable mortality rates and the local SEER tumor registry were used for comparison with the LLNL data. Possible sources of error include failure to detect a melanoma death, comparability of the LLNL workforce with the general California population, difficulty of properly adjusting for exclusion of the pre-July 1984 melanoma cases, the small number of expected melanoma deaths, and inclusion of LLNL terminees.

Failure to detect a melanoma death because of an error in matching the LLNL employee roster with the NDI was unlikely. The matching algorithm was robust using a best-fit analysis in case no exact match existed for name, sex, date of birth, and social security number. Moreover, all known melanoma cases diagnosed at LLNL during the study period have received follow-up, and none of these employees has died from melanoma. The number of melanoma cases shown in an allcancer incidence study conducted among LLNL employees in cooperation with the local SEER registry was similar to the number of melanoma cases shown by our study ${ }^{16}$. This finding makes remote the possibility of an undiscovered melanoma death in an LLNL employee diagnosed with melanoma during the study period.

Age-, sex-, and race-specific mortality rates for California should comprise a reasonable comparison group for LLNL employees in the absence of a matched or randomized control group. Number and type of nevi, family and personal history of melanoma and other types of skin cancer, are melanoma risk factors which cannot be assessed for lack of data, but there is some information on ultraviolet light exposure, and social class ${ }^{17}$. Sun exposure among LLNL employees is probably similar to exposure among the general California population, given that most LLNL employees live in the sunny north-central section of the state, where the climate resembles the climate found in 
most of the heavily populated areas of the state. Socioeconomic status and proportion of $\mathrm{PhD}$ awardees and college graduates in the LLNL workforce is much higher than in the general California population. Socioeconomic status and education are strong risk factors for melanoma incidence. Two population-based studies ${ }^{18,19}$ showed a two- to fourfold effect of socioeconomic status on incidence of melanoma. The effect on melanoma mortality is smaller. One study ${ }^{18}$ showed that highly educated persons had a 55\% higher melanoma-related mortality rate than did persons with less education. The high education level and high socioeconomic status among LLNL employees would produce a higher melanoma-related mortality rate than expected from age-, sex-, and race-based rates in the general California population. This difference makes the achieved mortality reduction more impressive.

To ensure inclusion of workers who terminated their LLNL employment because of metastatic melanoma, surveillance of melanoma-related deaths included persons who had terminated their LLNL employment as long as 3 years previously. This 3-year point is useful because more than $90 \%$ of mortality from systemically metastatic melanoma would probably occur by that point ${ }^{20}$. Inclusion of LLNL workforce terminees strengthens the comprehensiveness of our study. The extended follow-up added person-years to the study and thus added statistical significance to the reduction in mortality. Moreover, the statistical significance of the result would persist even if one death had occurred in the screened population during the study. This fact makes the result more robust, even with the small number of expected deaths. Because screening-derived benefit may be lost after employment, our original plan was to watch for an increase in mortality in the years after termination from LLNL; however, no additional deaths were observed in all the NDI data. We chose a limited post employment period of follow-up because we initially expected that the effect of screening would not be long lasting. 
The spike of melanoma cases which prompted creation of the screening program might have caused a decline in number of melanoma cases as an after-effect; instead, cases of melanoma (in situ plus invasive) continued to be diagnosed at a stable rate but with a reduction in the number of thicker lesions (Table 2). The striking and persistent reduction in the number of thick lesions with higher potential mortality ${ }^{21,22}$ during the screening program is the strongest support for the conclusion that the program resulted in real reduction of melanoma mortality. This is in contrast to other studies of melanoma screening which did not show any decrease in lesions over $0.75 \mathrm{~mm}^{345}$ One might also argue that the observed reduction in melanoma mortality was due to the elimination of an occupational cause of melanoma at LLNL. Intensive efforts were made before and during the study period to identify a causative agent. However, no such agent was ever found, nor were any preventive occupational measures instituted other than this surveillance program . Perhaps most importantly, our mortality comparison is not to prior LLNL mortality but to concurrent California mortality.

At least three factors reduced the number of thick melanoma lesions: (1) prompt recognition and removal of melanoma lesions by the medical staff, (2) the routine follow up of a few hundred employees at increased risk of melanoma, and (3) the knowledge of melanoma warning signs and skin awareness from mole counting among LLNL employees, many of whom presented themselves for examination after noting suspicious lesions. The importance of rapid recognition and biopsy of suspicious lesions is clear and the pathology data confirm the success of this part of the program.

The success of close follow up of dysplastic nevus and melanoma families in reducing the thickness new melanoma is well documented ${ }^{23}$ and this should be true for routinely screened LLNL persons with moderately elevated risk. Because most of the LLNL workforce was not examined in the voluntary screening program and most of those who took part were seen only once, we conclude that the employees' own self-examination helped to prevent development of thicker, higher-risk 
melanoma lesions. This same effect may have occurred among retirees. A recent large, population based melanoma case control study by Berwick suggested that self-examination reduced the relative risk of melanoma mortality by a striking $63 \%{ }^{24}$. Furthermore, the report predicted there would be an accompanying reduction of invasive melanoma incidence of $34 \%$. Remarkably our rate of invasive cases per 100,000 dropped 37\% (from 41 during pre-intervention to 26 during the study). Not surprisingly the melanoma cases who performed self examination in Berwick's study had mean Breslow thickness of $1.09 \mathrm{~mm}$ compared to 1.65 for those not doing skin checks. At LLNL there was a similar difference in mean case thickness which was $1.05 \mathrm{~mm}$ for the pre-study and $0.59 \mathrm{~mm}$ for the study period. The quality of the dermatologic staff at LLNL was probably similar to the motivated practitioners in other studies and screening by itself has not been successful in other studies. Therefore, the similarity between Berwick's report and ours suggests the high degree of melanoma awareness and self-examination was a major factor that led to the reduction in thick cases and mortality. Achieving this level of interest in the general population where there are many diseases of higher incidence and mortality may be very difficult.

Worksites are different from the community at large, and LLNL is a particularly unusual occupational setting because of the unique nature of the high-energy physics research taking place there. Located on a compact campus, the highly educated population was well informed about critical events. Two factors-a 1976 report describing local increase in melanoma cases and publication of several studies-markedly increased employee anxiety and interest in melanoma. Even before the program began, workforce awareness and early diagnosis may have surpassed the levels in the surrounding community ${ }^{25,26,27}$. At the outset of the study, which was accompanied by massive local publicity in 1984, 96\% of LLNL employees reported having some knowledge regarding melanoma. Throughout the study, the program staff performed almost 11,600 dermatologic examinations and received more than 7000 completed self-examination sheets. This 
well-motivated, intelligent workforce provided with easily accessible, free-of-charge, on site screening shows that reduction in melanoma mortality is possible through an education, self examination and limited screening program.

We believe that the mortality reduction we observed was probably the result of three preventive components: 1) the hands-on examination of about half the employees being screened, 2)long term screening of a small moderate risk population, and 3) the sensitization of nearly all employees, their spouses and caregivers to the menace of melanoma and the importance of noting suspicious lesions and counting moles. Our result emphasizes the usefulness of education at all levels in any future screening program. We look forward to larger, broader based, controlled studies to confirm this result.

\section{Authors' Contributions}

1. Jeffrey S. Schneider, MD participated in conception and design; analysis and interpretation of the data; drafting of the article; and screened the study patients.

2. Dan H. Moore II, PhD participated in study design; analysis and interpretation of the data; drafting the statistical portion of the article.

3. Mortimer L. Mendelsohn, MD, PhD was study sponsor and obtained research funding and participated in study design; collection and assembly of data; provided study patients and materials; analysis and interpretation of data; drafting the article.

\section{$\underline{\text { Conflict of Interest Statement }}$}

None declared. 


\section{Acknowledgments}

Richard W. Sagebiel, MD, of the University of California San Francisco Melanoma Center, helped set up the screening project and evaluated the biopsy specimen slides. Robert A. Hiatt, MD, $\mathrm{PhD}$, reviewed the manuscript.

Research support, including travel, was provided by the U.S. Department of Energy, which had no role in the study design.

We thank Karen Martin, RN, who was nurse coordinator for the project; and the Melanoma Clinic Fellows at the University of California, San Francisco.

The Kaiser Foundation Hospitals Medical Editing Department provided editorial assistance.

This work was performed under the auspices of the U. S. Department of Energy by University of California, Lawrence Livermore National Laboratory under Contract W-7405-ENG-48. 
Table 1. Distribution of deaths from melanoma (1984-1996) in 5 San Francisco Bay Area counties stratified by diagnosis date before July 1984 .

Deaths in cases diagnosed before July 1984

\begin{tabular}{cccc} 
Year & $\begin{array}{c}\text { Total } \\
\text { Deaths, number }\end{array}$ & Number (\%) & Smoothed Percentage* \\
\hline 1984 & 79 & $70(89)$ & $88 \%$ \\
1985 & 71 & $48(68)$ & $66 \%$ \\
1986 & 61 & $27(44)$ & $50 \%$ \\
1987 & 71 & $27(38)$ & $38 \%$ \\
1988 & 72 & $26(36)$ & $30 \%$ \\
1989 & 80 & $10(13)$ & $24 \%$ \\
1990 & 81 & $19(23)$ & $20 \%$ \\
1991 & 98 & $20(20)$ & $16 \%$ \\
1992 & 73 & $10(14)$ & $14 \%$ \\
1993 & 92 & $7(8)$ & $13 \%$ \\
1994 & 83 & $9(11)$ & $11 \%$ \\
1995 & 89 & $4(4)$ & $10 \%$ \\
1996 & 104 & $14(13)$ & $10 \%$ \\
\hline
\end{tabular}

*Used to calculate number of deaths expected in LLNL employees diagnosed with melanoma before July 1984. 
Table 2. Number and incidence of melanoma before and after 1984 implementation of prevention program at Lawrence Livermore National Laboratory.

\begin{tabular}{|c|c|c|c|c|}
\hline \multirow[b]{2}{*}{ Year } & \multicolumn{3}{|c|}{ Thickness category } & \multirow[b]{2}{*}{$>1.50 \mathrm{~mm}$} \\
\hline & In situ & $\leq 0.75 \mathrm{~mm}$ & $>0.75$ to $1.50 \mathrm{~mm}$ & \\
\hline \multicolumn{5}{|c|}{ Number of lesions } \\
\hline $1969-84$ & 7 & 23 & 12 & 6 \\
\hline 1984 & 3 & 0 & 2 & 0 \\
\hline 1985 & 4 & 2 & 1 & 0 \\
\hline 1986 & 1 & 3 & 0 & 0 \\
\hline 1987 & 1 & 1 & 1 & 0 \\
\hline 1988 & 1 & 1 & 0 & 0 \\
\hline 1989 & 3 & 3 & 1 & 0 \\
\hline 1990 & 1 & 2 & 0 & 0 \\
\hline 1991 & 4 & 2 & 0 & 0 \\
\hline 1992 & 1 & 2 & 0 & 0 \\
\hline 1993 & 2 & 2 & 0 & 0 \\
\hline 1994 & 1 & 1 & 0 & 0 \\
\hline 1995 & 1 & 0 & 0 & 0 \\
\hline 1996 & 3 & 4 & 0 & 0 \\
\hline 1984-96 & 26 & 23 & 5 & 0 \\
\hline \multicolumn{5}{|c|}{ Incidence per 100,000 person-years } \\
\hline $1969-84$ & 6.99 & 22.95 & $11.98^{*}$ & $5.99 *$ \\
\hline $1984-96$ & 24.00 & 21.23 & $4.62 *$ & 0.00 \\
\hline
\end{tabular}

$* \mathrm{p}=0.02$ for the difference between 1969-84 and 1984-96 crude incidence of melanoma $>0.75$ (Miettinen's exact test). 
References

${ }^{1}$ National Cancer Institute. Surveillance, Epidemiology, and End Results [website]. Available from: http://seer.cancer.gov/csr/1975 2001/results_merged/sect_16 melanoma.pdf page2-3. (accessed July 15, 2004).

${ }^{2}$ Koh HK, Norton LA, Geller AC, Sun T, Rigel DS, Miller DR, et al. Evaluation of the American Academy of Dermatology's National Skin Cancer Early Detection and Screening Program. J Am Acad Dermatol 1996 Jun;34(6):971-8.

${ }^{3}$ Melia J, Moss S, Frost T, Graham-Brown R, Hunter JAA, et al. The relation between mortality from malignant melanoma and early detection in the Cancer Research Campaign Mole Watcher Study. Br J Cancer 2001 85(6):803-807.

${ }^{4}$ MacKie RM, Hole D, Hunter JA, Rankin R, Evans A, McLaren K, et al. Cutaneous malignant melanoma in Scotland: incidence, survival, and mortality, 1979-94. The Scottish Melanoma Group. BMJ 1997 Nov 1;315(7116):1117-21.

${ }^{5}$ MacKie RM, Bray CA, Hole DJ, Morris A, Nicolson M, Evans R, Doherty V, Vesty J. Incidence of and survival from malignant melanoma in Scotland: an epidemiological study. Lancet 2002 Aug 24; 360:587-91.

${ }^{6}$ Cristofolini M, Zumiani G, Boi S, Piscioli F. Community detection of early melanoma [letter]. Lancet 1986 Jan 18;1(8473):156.

${ }^{7}$ Cristofolini M, Bianchi R, Boi S, DeCarli A, Micciolo R, Cristofolini P, et al. Effectiveness of the health campaign for the early diagnosis of cutaneous melanoma in Trentino, Italy. J Dermatol Surg Oncol 1993 Feb;19(2):117-20.

${ }^{8}$ Aitken JF, Elwood JM, Lowe JB, Firman DW, Balanda KP, Ring IT. A randomised trial of population screening for melanoma. J Med Screen 2002;9(1):33-7.

${ }^{9}$ Austin DF, Reynolds PJ, Snyder MA, Biggs MW, Stubbs HA. Malignant melanoma among employees of Lawrence Livermore National Laboratory. Lancet 1981 Oct 3;2(8249):712-6.

${ }^{10}$ Lawson DD, Moore DH 2nd, Schneider JS, Sagebiel RW. Nevus counting as a risk factor for melanoma: comparison of self-count with count by physician. J Am Acad Dermatol 1994 Sep;31(3 Pt 1):438-44.

${ }^{11}$ Precursors to Malignant Melanoma. NIH Consensus Statement Online 1983 Oct 24-26 [cited year month day];4(9):1-14.

12 Diagnosis and Treatment of Early Melanoma. NIH Consensus Statement Online 1992 Jan 27-29

[cited year month day];10(1):1-26.

${ }^{13}$ Schneider JS, Moore DH 2nd, Sagebiel RW. Risk factors for melanoma incidence in prospective follow-up. The importance of atypical (dysplastic) nevi. Arch Dermatol 1994 Aug;130(8):1002-7.

${ }^{14}$ Expert Health Data Programming, Inc. Health data software and health statistics [website]. Available from: http://www.ehdp.com (accessed April 2001 ).

${ }^{15}$ Moore DH $2^{\text {nd }}$, Bennett DE. Mortality among the employees of the Lawrence Livermore National Laboratory. Energy and Technology Review 1984 Dec:9-19.

${ }^{16}$ Whorton D, Moore D, Seward J, Noonan K, Mendelsohn M. Cancer incidence rates among Lawrence Livermore National Laboratory (LLNL) employees: 1974-1997. Am J Industrial Med 2004 45:24-33.

${ }^{17}$ Berwick M. Epidemiology: current Trends, risk factors, and environmental concerns. In: Balch CM, Houghton AN, Sober AJ, Soong SJ, editors. Cutaneous melanoma. 3rd ed. St. Louis: Quality Medical Publishing; 1998. p. 551-71. 
${ }^{18}$ MacKie RM, Hole DJ. Incidence and thickness of primary tumours and survival of patients with cutaneous malignant melanoma in relation to socioeconomic status. BMJ 1996 May

4;312(7039):1125-8.

${ }^{19}$ Geller AC, Miller DR, Lew RA, Clapp RW, Wenneker MB, Koh HK. Cutaneous melanoma mortality among the socioeconomically disadvantaged in Massachusetts. Am J Public Health 1996 Apr:86(4):538-44.

${ }^{20}$ Balch CM, Soong SJ, Murad TM, Smith JW, Maddox WA, Durant JR. A multifactorial analysis of melanoma. IV. Prognostic factors in 200 melanoma patients with distant metastases (stage III). J Clin Oncol 1983 Feb;1(2):126-34.

${ }^{21}$ Balch CM, Buzaid AC, Soong SJ, Atkins MB, Cascinelli N, Coit DG, et al. Final version of the American Joint Committee on Cancer staging system for cutaneous melanoma. J Clin Oncol 2001 Aug 15;19(16):3635-48.

${ }^{22}$ Balch CM, Soong SJ, Gershenwald JE, Thompson JF, Reintgen DS, Cascinelli N, et al. Prognostic factors analysis of 17,600 melanoma patients: validation of the American Joint Committee on Cancer melanoma staging system. J Clin Oncol 2001 Aug 15;19(16):3622-34.

${ }^{23}$ Masri GD. Clark WH Jr. Guerry D 4th. Halpern A. Thompson CJ. Elder DE. Screening and surveillance of patients at high risk for malignant melanoma result in detection of earlier disease. Journal of the American Academy of Dermatology. 1990 22(6 Pt 1):1042-8.

${ }^{24}$ Berwick M, Begg CB, Fine JA, Roush GC, Barnhill RL. Screening for cutaneous melanoma by skin self-examination. J Natl Cancer Inst 1996 Jan 3;88(1):17-23.

${ }^{25}$ Schneider JS, Sagebiel RW, Moore DH 2nd, Lawton GM. Melanoma surveillance and earlier diagnosis. Lancet 1987 Jun 20;1(8547):1435.

${ }^{26}$ Schneider JS, Moore DH 2nd, Sagebiel RW. Early diagnosis of cutaneous malignant melanoma at Lawrence Livermore National Laboratory. Arch Dermatol 1990 Jun;126(6):767-9.

${ }^{27}$ Hiatt RA, Krieger N, Sagebiel RW, Clark WH Jr, Mihm MC Jr. Surveillance bias and the excess risk of malignant melanoma among employees of the Lawrence Livermore National Laboratory.

Epidemiology 1993 Jan;4(1):43-7. 
Table 3. Employee population by year and expected deaths from melanoma in men at LLNL (1984-1996)

\begin{tabular}{|c|c|c|c|c|c|c|c|c|c|c|c|c|c|}
\hline & \multicolumn{13}{|c|}{ Year } \\
\hline & 1984 & 1985 & 1986 & 1987 & 1988 & 1989 & 1990 & 1991 & 1992 & 1993 & 1994 & 1995 & 1996 \\
\hline Total & 6510 & 6578 & 6511 & 6999 & 6909 & 6821 & 6691 & 6557 & 6568 & 6247 & 5937 & 5851 & 5576 \\
\hline White & 5748 & 5778 & 5695 & 6090 & 5986 & 5889 & 5757 & 5618 & 5605 & 5301 & 5009 & 4923 & 4678 \\
\hline Asian & 274 & 292 & 304 & 342 & 352 & 359 & 363 & 367 & 379 & 372 & 365 & 367 & 356 \\
\hline Hispanic & 268 & 279 & 281 & 311 & 313 & 314 & 313 & 313 & 320 & 313 & 306 & 305 & 294 \\
\hline Black & 221 & 229 & 231 & 256 & 258 & 258 & 257 & 258 & 264 & 260 & 256 & 256 & 248 \\
\hline \multicolumn{14}{|c|}{ Expected Deaths } \\
\hline White & $\odot .309$ & $\odot .314$ & 0.318 & $\odot .342$ & $\odot .342$ & 0.347 & 0.346 & $\odot .339$ & $\odot .340$ & 0.312 & 0.285 & $\odot .287$ & $\odot .279$ \\
\hline Asian & 0.001 & $\odot .001$ & 0.001 & $\odot .001$ & $\odot . \odot \odot 1$ & $\odot .001$ & $\odot .001$ & $\odot .001$ & $\odot . \odot \odot 2$ & $\odot .001$ & 0.001 & $\odot .001$ & $\odot .001$ \\
\hline Hispanic & $\odot .002$ & 0.002 & 0.002 & $\odot .0 \odot 2$ & $\odot .0 \odot 2$ & 0.002 & 0.002 & $\odot .002$ & $\odot .0 \odot 2$ & 0.002 & 0.002 & 0.002 & $\odot .0 \odot 2$ \\
\hline Black & 0.001 & 0.001 & 0.001 & $\odot .001$ & $\odot .001$ & 0.001 & 0.001 & 0.001 & $\odot .001$ & 0.001 & 0.001 & 0.001 & 0.001 \\
\hline Total & 0.312 & $\odot .318$ & 0.322 & $\odot .346$ & 0.347 & $\odot .351$ & $\odot .350$ & $\odot .344$ & 0.345 & 0.317 & 0.290 & $\odot .291$ & $\odot .284$ \\
\hline Adjusted & $\odot .037$ & $\odot .108$ & 0.161 & $\odot .213$ & $\odot .243$ & $\odot .267$ & 0.281 & $\odot .287$ & $\odot .296$ & 0.277 & 0.257 & $\odot .261$ & 0.256 \\
\hline total & & & & & & & & & & & & & \\
\hline
\end{tabular}


Table 4. Employee population and expected deaths from melanoma in women at LLNL (1984-1996)

\begin{tabular}{|c|c|c|c|c|c|c|c|c|c|c|c|c|c|}
\hline & \multicolumn{13}{|c|}{ Year } \\
\hline & 1984 & 1985 & 1986 & 1987 & 1988 & 1989 & 1990 & 1991 & 1992 & 1993 & 1994 & 1995 & 1996 \\
\hline Total & 1587 & 1722 & 1852 & 2140 & 2288 & 2396 & 2439 & 2520 & 2682 & 2663 & 2593 & 2605 & 2480 \\
\hline White & 1324 & 1420 & 1511 & 1726 & 1827 & 1895 & 1911 & 1955 & 2063 & 2027 & 1949 & 1944 & 1833 \\
\hline Asian & 75 & 89 & 104 & 129 & 146 & 162 & 172 & 186 & 206 & 213 & 216 & 223 & 219 \\
\hline Hispanic & 98 & 112 & 126 & 152 & 169 & 182 & 191 & 204 & 224 & 230 & 233 & 238 & 232 \\
\hline Black & 89 & 100 & 111 & 133 & 146 & 157 & 164 & 174 & 189 & 194 & 195 & 200 & 195 \\
\hline \multicolumn{14}{|c|}{ Expected Deaths } \\
\hline White & 0.031 & 0.034 & 0.037 & 0.042 & 0.045 & $\odot .048$ & $\odot . \odot 49$ & 0.050 & 0.053 & 0.051 & 0.048 & 0.049 & 0.047 \\
\hline Asian & 0.000 & $\odot .00 \odot$ & 0.000 & $\odot .00 \odot$ & $0.0 \odot \odot$ & 0.000 & $\odot . \odot \odot \odot$ & $\odot .000$ & $\odot .001$ & 0.001 & 0.001 & 0.001 & 0.001 \\
\hline Hispanic & $0.0 \odot \odot$ & $\odot . \odot \odot \odot$ & 0.001 & $\odot .0 \odot 1$ & 0.001 & 0.001 & $\odot .001$ & $\odot .001$ & 0.001 & 0.001 & 0.001 & 0.001 & 0.001 \\
\hline Black & $\odot . \odot \odot \odot$ & $\odot . \odot \odot \odot$ & $\odot . \odot \odot \odot$ & $\odot .001$ & 0.001 & $\odot .001$ & $\odot .001$ & $\odot .001$ & $\odot .001$ & 0.001 & 0.001 & 0.001 & $\odot .001$ \\
\hline Total & 0.032 & 0.035 & 0.038 & $\odot .043$ & 0.047 & 0.050 & 0.051 & 0.052 & 0.055 & 0.053 & 0.051 & 0.051 & 0.049 \\
\hline Adjusted & 0.004 & 0.012 & 0.019 & $\odot .027$ & $\odot .033$ & $\odot .038$ & $\odot .041$ & $\odot .044$ & $\odot .048$ & 0.047 & 0.045 & 0.046 & 0.044 \\
\hline
\end{tabular}

total 